\title{
Perancangan Model Balancing Robot untuk Sarana Transportasi Tenaga Medis
}

\author{
M. Munadi ${ }^{1}$, Mochammad Ariyanto ${ }^{1}$, Royyan Saputra' ${ }^{1}$, Joga D. Setiawan ${ }^{1}$
}

${ }^{1}$ Departemen Teknik Mesin, Universitas Diponegoro

J1. Prof. Sudharto, SH., Tembalang, Semarang, 50275

Email korespondensi: munadi@undip.ac.id

\begin{abstract}
Abstrak
Robot telah menjadi peralatan mekanik yang dapat melakukan tugas fisik, baik dengan pengawasan atau menggunakan program yang telah didefinisikan terlebih dulu (kecerdasan buatan). Salah satu jenis robot adalah mobile robot yang memiliki mekanisme penggerak berupa roda (wheel) dan atau kaki (leg), sehingga dapat berpindah tempat dari suatu tempat ke tempat yang lain. Salah satu jenis mobile robot diantaranya adalah balancing robot yang beroda dua dan dapat menyeimbangkan diri terhadap permukaan bumi. Pada penelitian ini, kami akan mencoba merancang model balancing-robot yang dalam pengembangan di masa depan dapat digunakan di rumah sakit oleh tenaga medis sebagai sarana transportasi yang ramah lingkungan. Hal ini karena tenaga medis sering sekali harus mobile dalam memantau pasien. Terkait hal tersebut, agar model balancing robot dapat seimbang maka digunakan salah satu jenis kontroler Adapun sensor yang digunakan adalah sensor accelerometer NI myRIO untuk mendeteksi perubahan sudut, dan sensor gyroscope untuk mendeteksi kecepatan sudut. Agar balancing robot dapat seimbang digunakan metode kontrol Proportional-Integral untuk mengatur kecepatan dana arah putar motor DC. Tuning parameter kontrol Proporsional-Integral dilakukan dengan dua metode yaitu metode Ziegler-Nichols dan trial and error. Hasil tuning dari Proporsional Integral yang baik adalah nilai gain $K_{p}=5$ dan $K_{i}=0,001$.
\end{abstract}

Kata kunci: balancing robot, proporsional-integral, accelerometer, gyroscope.

\begin{abstract}
Robots have become mechanical equipment that can perform physical tasks, either by monitoring or using predefined programs (artificial intelligence). One type of robot is a mobile robot that has a driving mechanism in the form of a wheel and leg so that it can move from one place to another. One type of mobile robot includes balancing a two-wheeled robot and can balance itself to the surface of the earth. In this study, we will try to design a model of balancing robots that in future development can be used in hospitals by medical personnel as an environmentally friendly means of transportation. This is because medical personnel often have to be mobile in monitoring patients. Related to this, so that the model of balancing robot can be balanced, one type of controller is used. The sensor used is the NI myRIO accelerometer sensor to detect angular changes, and the gyroscope sensor to detect angular velocity. In order to balance the model of balancing robot, the Proportional-Integral control method is used to adjust the speed of the DC direction of the rotating motor. Tuning Proportional-Integral control parameters is done by two methods, namely Ziegler-Nichols method and trial and error. The good tuning from Proportional Integral is the gain value $K_{p}=5$ and $K_{i}=0.001$.
\end{abstract}

Keywords: balancing robot, proporsional-integral, accelerometer, gyroscope.

\section{Pendahuluan}

Penelitian dan pengembangan tentang robot telah berkembang dengan cepat. Pengembangan robot pada awalnya dimulai tahun 1940-an ketika Argonne National Laboratories di Oak Ridge, Amerika, memperkenalkan sebuah mekanisme robotik yang diberi nama master-slave manipulator. Robot tersebut dipakai untuk menangani material radioaktif. Kemudian di tahun 1950-an, Unimation Incorporated memperkenalkan produk robot komersial pertama. Selanjutnya, pada pertengahan tahun 1960-an produk robot dipakai dalam kegiatan industri, maka muncul istilah industrial robot dan robot manipulator. Dewasa ini definisi robot industri sudah bergeser karena teknologi mobile robot sudah dipakai meluas sejak awal tahun 1980-an. Mobile robot telah diaplikasikan di berbagai bidang, seperti eksplorasi, pencarian dan penyelamatan, penanganan material dan pendidikan [1]. Selain itu, mobile robot dapat digunakan sebagai robot utilitas, misalnya pada penggunaan robot untuk kebersihan [2], inspeksi [3], dan sarana transportasi di rumah sakit [4].

Bila dibandingkan dengan jenis robot yang lain, misalnya robot berkaki memiliki struktur mekanika dan dinamika yang lebih rumit, sedangkan mobile robot lebih sederhana, mudah dirancang dan hemat energi [5]. Mobile robot diklasifikasikan menjadi dua berdasarkan lingkungan tempat robot tersebut bekerja 
dan alat yang digunakan untuk bergerak. Berdasarkan lingkungan tempat robot tersebut bekerja, mobile robot terbagi menjadi empat macam, yaitu robot yang bekerja di atas permukaan tanah (land robot), contohnya robot udara atau Unmanned Aerial Vehicle (UAV), Autonomous Underwater Vehicles (AUVs), robot yang bekerja pada lingkungan kutub, dan robot yang bekerja pada kondisi permukaan tanah. Sedangkan berdasarkan alat yang digunakan untuk bergerak, mobile robot terbagi menjadi robot berlengan (berkaki-lengan atau kaki yang menyerupai manusia ataupun hewan), dan robot beroda [6].

Salah satu contoh penggunaan mobile robot adalah balancing robot beroda dua yang dikembangkan oleh beberapa peneliti [7, 8]. Balancing robot beroda dua merupakan robot yang mencoba menyeimbangkan dua roda seolah-olah sebagai pendulum terbalik. Pada saat gaya diberikan kepada robot, maka robot menjadi miring. Selanjutnya motor akan memberikan gaya perlawanan yang sesuai sehingga robot tetap dalam keadaan tegak. Tanpa adanya gaya yang sesuai, robot akan jatuh [9]. Balancing robot juga telah dikembangkan menjadi salah satu model transportasi yang bernama "Segway". Dimana harganya relatif lebih mahal disbanding sepeda tetapi memiliki kelebihan bentuk yang kecil dan compact.

Saat ini pengembangan sarana transportasi yang ramah lingkungan digalakkan. Misalnya sarana sarana transportasi di lingkungan rumah sakit yang biasanya menggunakan sepeda untuk mengurangi rasa kelelahan tenaga medis dalam memeriksa/mengontrol pasien di area rumah sakit yang luas. Akan tetapi, penggunaan sepeda memiliki keterbatasan diantaranya ukuran yang besar sehingga kurang fleksibel khususnya bila tenaga medis harus berjalan dari lantai yang satu ke lantai yang lain. Oleh sebab itu, penelitian ini akan melakukan perancangan model balancing robot sebagai tahap awal pengembanagn sarana transportasi tenaga medis. Model balancing robot ini menggunakan sensor gyroscope dan accelerometer sebagai inputnya. Dari sinyal yang diperoleh kemudian diproses ke sistem motor DC sebagai aktuator yang diembedded pada mikrokontroller NI myRIO.

\section{Sistem Hardware Model Balancing Robot}

Model balancing robot yang dirancang merupakan salah satu konsep pengembangan two wheel selfbalancing mobile robot. Prinsip kerjanya mirip dengan segway, sedangkan perbedaanya terletak pada tujuan fungsionalnya. Untuk mencapai tujuan tersebut, kegiatan penelitian diawali dengan membuat drawing balancing robot yang ditunjukkan pada Gambar 1.

Adapaun sistem elektrik model balancing robot terdiri dari beberapa komponen elektronika, diantarnya mikrokontroler (NI myRIO), motor DC, sumber daya, motor driver, ubec, dan sensor gyroscope. Beberapa komponen tersebut disusun membentuk sebuah diagram desain hardware (wiring) model balancing robot yang ditunjukkan pada Gambar 2. Sedangkan diagram blok sistem model balancing robot ditunjukan pada Gambar 3.

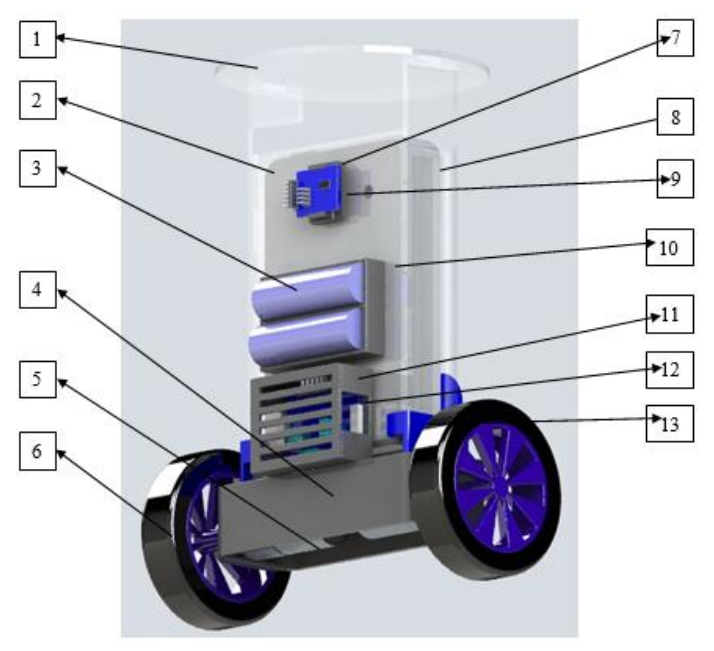

Gambar 1. Desain model balancing robot

Keterangan :
1. Chassis atas
9. Sensor gyroscope
2. Chassis utama
10. Tempat baterai
3. Baterai belakang
4. Dudukan motor DC
5. Motor DC
11. Dudukan
6. Roda
PmodDHBI
7. Dudukan gyroscope
8. NI myRIO
2. PmodHBI
13. Tempat baterai depan

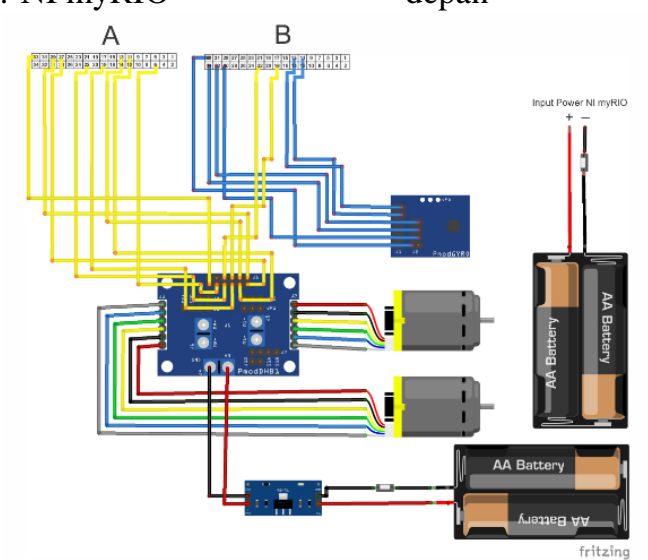

Gambar 2. Diagram wiring model balancing robot.

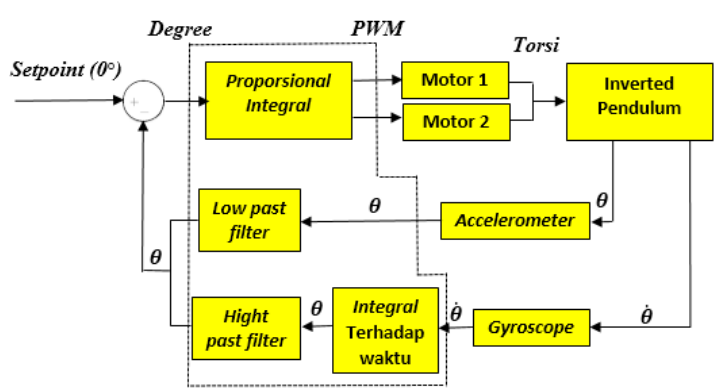

Gambar 3. Diagram blok sistem model balancing robot. 


\section{Pemprograman Model Balancing Robot}

Setelah rangkaian hardware selesai dibuat, dilakukanlah pemograman menggunakan software LabVIEW 2015 for NI myRIO. Software LabVIEW berfungsi sebagai sebagai human machine interface (HMI). Program yang dibuat ditunjukkan pada Gambar 4-8. Gambar 4 menunjukkan front panel model balancing robot dimana jalannya program dimulai dari masuknya sinyal input berupa tegangan. Disini terdapat empat sinyal input yang masingmasing didiskripsikan sebagai angle filter, accelerometer, gyroscope dan encoder, dimana masing-masing masuk pada pin analog Input.

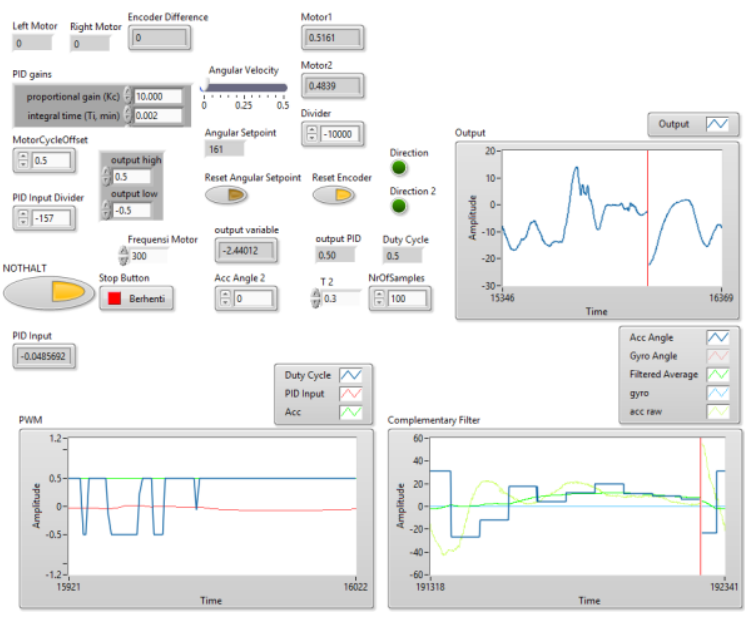

Gambar 4. Front panel model balancing robot.

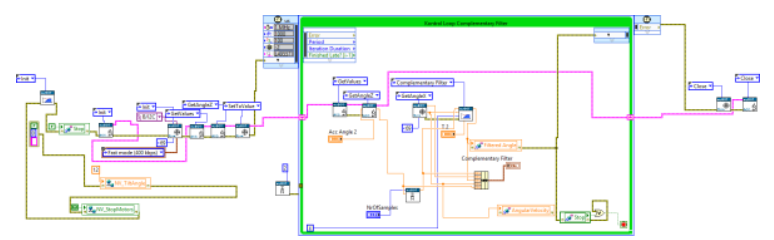

Gambar 5. Diagram blok complementary filter sensor accelerometer dengan sensor gyroscope.

Gambar 5 menunjukkan pemrograman untuk time loop complementary filter sensor accelerometer dengan sensor gyroscope yang digunakan untuk pembacaan sensor accelerometer dan gyroscope. Pembacaan awal yaitu input dari angle filter, accelerometer dan gyroscope. Adapun analog input sensor gyroscope terdapat pada pin I2C port $\mathrm{B} \mathrm{Ni}$ myRIO. Sensor accelerometer membaca sudut pada sumbu $\mathrm{Z}$ dan sensor gyroscope membaca sudut pada sumbu X. Complementary filter dibaca pada ikon angel filter. Pada ikon angel filter dapat menentukan nilai alpha dan filtered angel. Pada gambar tersebut, ditunjukkan shared variable yang berfungsi sebagai transfer dari while loop A ke while loop B yaitu filtered angle dan angular velocity (sumbu $\mathrm{X}$ gyroscope).

Gambar 7 menunjukkan time loop kontrol PWM motor DC. Blok diagram membaca keluaran dari motor DC yang digunakan pada balancing robot.
Digital output pada time loop ini berfungsi sebagai pengendali arah putaran motor DC.

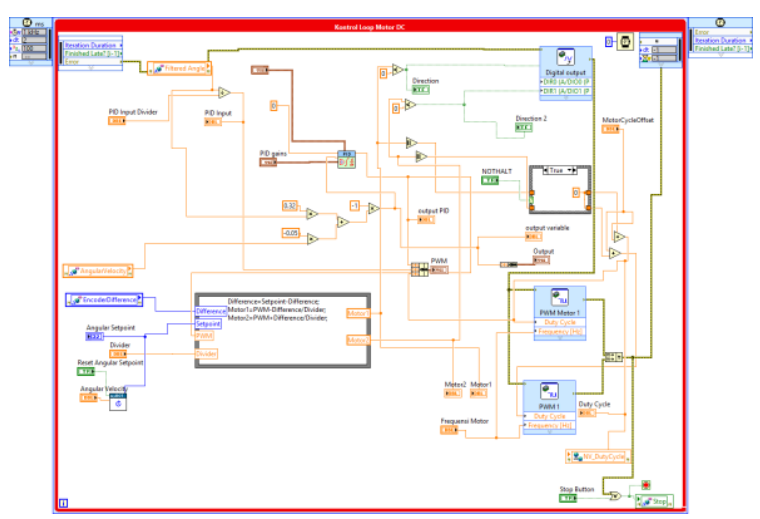

Gambar 6. Diagram blok kontrol PWM motor DC.

PWM output pada time loop ini memiliki 2 PWM output, dikarenakan ada 2 motor DC yang digerakkan. Adapun kontrol PID pada balancing robot terdapat di diagram blok ini.

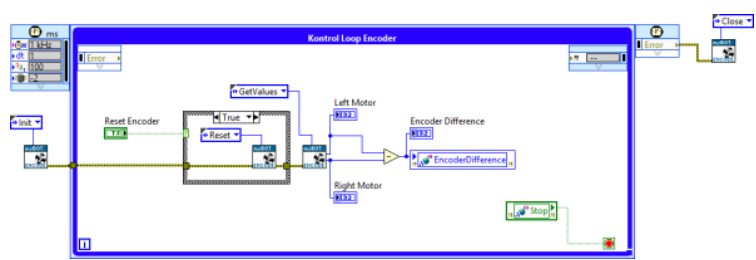

Gambar 7. Diagram blok encoder.

Pada NI myRIO, disetiap port A, B, dan C terdapat satu input yang dapat digunakan sebagai input encoder. Adapun input yang digunakan pada port A dan port B. Time loop encoder memiliki ikon shared variable yang berfungsi untuk mentarnsfer data ke time loop kontrol PWM motor DC berupa encoder diference. Selanjutnya, secara keseluruhan diagram block model balancing robot ditunjukkan pada Gambar 8.

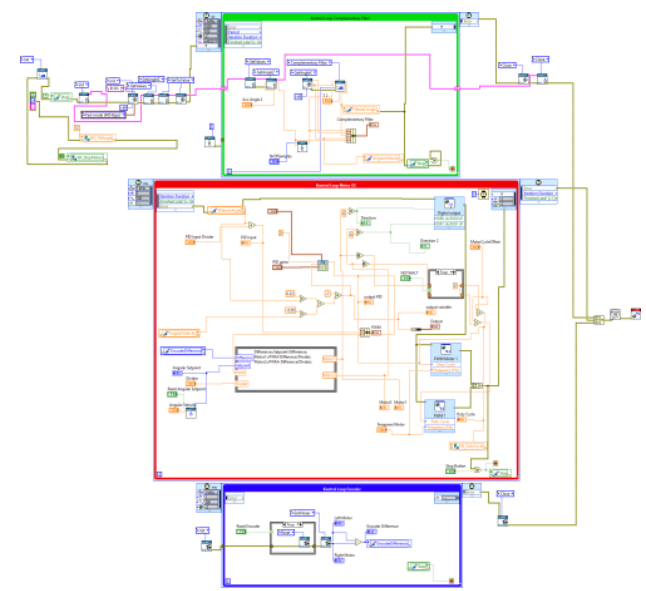

Gambar 8. Diagram blok model balancing robot.

\section{Hasil dan Pembahasan}

Sistem kontrol model balancing robot menggunakan sistem kontrol PID. Sistem kontrol PID merupakan 
kontroler yang dapat membantu menentukan tingkat kepresisian suatu sistem instrumentasi dalam mencapai tujuan dengan karakteristik adanya umpan balik (feedback) pada sistem tesebut [10, 11]. Sistem kontrol PID terdiri dari tiga buah cara pengaturan yaitu kontrol Proportional (P), Derivative (D), dan Integral (I). Dalam perancangan sistem kontroler PID yang perlu dilakukan adalah mengatur gain kontroler $\left(\mathrm{K}_{\mathrm{p}}, \mathrm{K}_{\mathrm{i}}\right.$, dan $\left.\mathrm{K}_{\mathrm{d}}\right)$ agar tanggapan sinyal keluaran sistem terhadap masukan tertentu sebagaimana yang diinginkan. Selanjutnya, pengujian model balancing robot dilakukan pada dua perangkat robot, yaitu perangkat keras meliputi pengujian sensor accelerometer dan gyroscope, serta perangkat lunak yang meliputi pengujian algoritma complementary filter dan tuning gain PID.

\section{Perangkat Keras}

Pada board NI myRIO, terdapat beberapa peripheral yang umum dapat digunakan. Diantaranya adalah sensor accelerometer. Sensor accelerometer pada NI myRIO memerlukan kalibrasi agar mendapatkan hasil auto zero. Pengujian sensor accelerometer dilakukan dengan cara membandingkan keluarannya yang berupa sudut kemiringan terhadap busur derajat. Sumbu yang digunakan pada percobaan ini adalah sumbu Z. Hal ini karena penempatan NI myRIO pada posisi berdiri. Untuk mendapatkan nilai sumbu Z, maka dapat dicari dengan menggunakan Persamaan (1). Adapun kemampuan sensor accelerometer dalam membaca sudut kemiringan mempunyai jangkauan kerja sebesar $45^{\circ}$ dan $-45^{\circ}$. Dikarenakan balancing robot membutuhkan pembacaan sudut kemiringan sekitar $20^{\circ}$ sampai $-20^{\circ}$, maka pengujian sudut kemiringan sensor accelerometer dilakukan pada jangkauan $-90^{\circ}$ sampai $90^{\circ}$ dengan kelipatan 10. Data hasil pengukuran yang dilakukan ditunjukkan pada Tabel 1.

Sumbu $Z=\left(\frac{180}{\pi} \times \arctan 2(y, z)+\pi\right)-\frac{270}{90} \times 157-$ offset (1)

dimana sumbu $\mathrm{Z}$ adalah nilai keluaran dari sumbu $\mathrm{Z}$, untuk offset yang dimaksud adalah nilai offset sensor, dan y serta z menunjukkan sumbu y dan z.

Berdasarkan Tabel 1 diperoleh data bahwa sensor accelerometer pada NI myRIO masih terdapat kesalahan (error). Hal ini dapat disebabkan oleh beberapa faktor, diantaranya adalah proses pengukuran dari busur dan accelerometer yang kurang tepat, pembulatan dalam pemograman, dan noise yang dihasilkan oleh sensor accelerometer itu sendiri. Beberapa nilai sudut kemiringan yang dideteksi oleh sensor accelerometer ditampilkan dalam bentuk grafik dengan waktu tunggu $10 \mathrm{~ms}$. Adapun sudut kemiringan yang ditampilkan pada grafik bernilai $0^{\circ}, 45^{\circ}$, dan $-45^{\circ}$. Grafik pengujian sudut sensor accelerometer ditunjukkan pada Gambar 9.
Tabel 1. Hasil pengukuran kemiringan sudut sensor accelerometer.

\begin{tabular}{ccc}
\hline No. & Busur Derajat & Sudut Sensor Accelerometer \\
\hline 1 & $-90^{\circ}$ & $-152.7^{\circ}$ \\
2 & $-80^{\circ}$ & $-117.4^{\circ}$ \\
3 & $-70^{\circ}$ & $-97.6^{\circ}$ \\
4 & $-60^{\circ}$ & $-66.5^{\circ}$ \\
5 & $-50^{\circ}$ & $-53.6^{\circ}$ \\
6 & $-40^{\circ}$ & $-46.5^{\circ}$ \\
7 & $-30^{\circ}$ & $-32.4^{\circ}$ \\
8 & $-20^{\circ}$ & $-12.2^{\circ}$ \\
9 & $-10^{\circ}$ & $-9.4^{\circ}$ \\
10 & $0^{\circ}$ & $0.8^{\circ}$ \\
11 & $10^{\circ}$ & $11.2^{\circ}$ \\
12 & $20^{\circ}$ & $21.3^{\circ}$ \\
13 & $30^{\circ}$ & $36.2^{\circ}$ \\
14 & $40^{\circ}$ & $44.1^{\circ}$ \\
15 & $50^{\circ}$ & $53.5^{\circ}$ \\
16 & $60^{\circ}$ & $64.2^{\circ}$ \\
17 & $70^{\circ}$ & $97.2^{\circ}$ \\
18 & $80^{\circ}$ & $121.6^{\circ}$ \\
19 & $90^{\circ}$ & $142.5^{\circ}$ \\
\hline
\end{tabular}

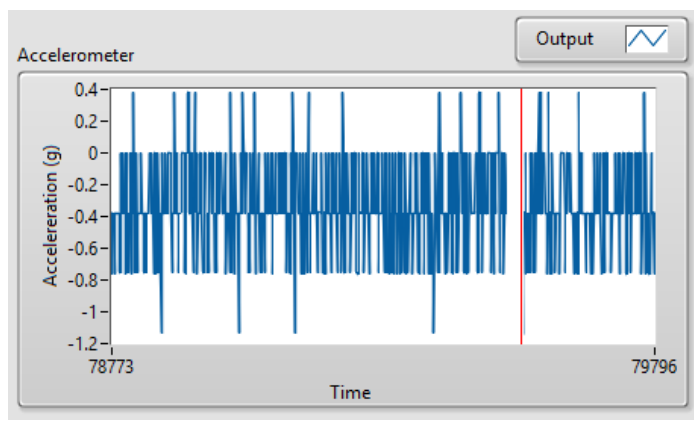

(a)

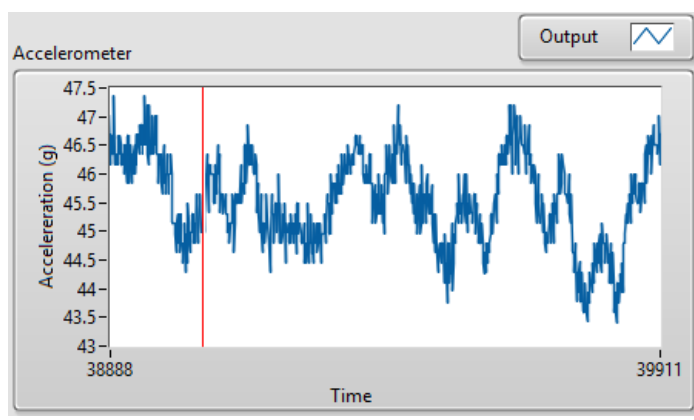

(b)

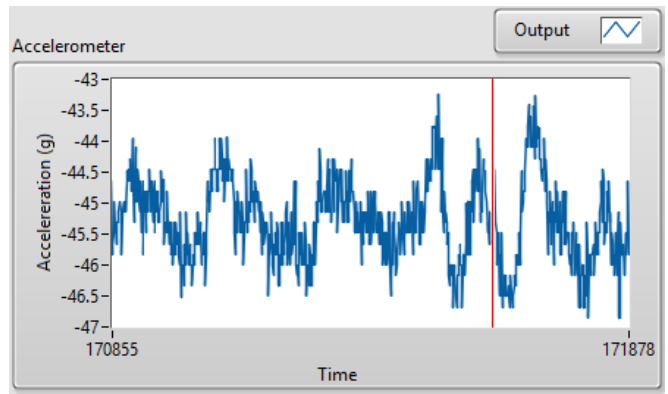

(c)

Gambar 9. Grafik sensor accelerometer mendeteksi sudut kemiringan (a) $0^{\circ}$; (b) $45^{\circ}$; (c) $-45^{\circ}$ 
Pengujian dilakukan menggunakan sensor gyroscope untuk melihat kecepatan sudut yang dideskripsikan dalam bentuk grafik. Hasil pengujian ditunjukan pada Gambar 10 dimana menggunakan waktu tunggu 100 ms. Sumbu yang digunakan pada sensor gyroscope yaitu pada sumbu X. Hal ini dikarenakan sensor gyroscope yang dipasang pada balancing robot ditempatkan pada sumbu X. Gambar 10 (a) menunjukan grafik angle rate sensor gyroscope dalam kedaan diam atau tidak melakukan rotasi, sehingga kecepatan rotasi pada sensor gyroscope adalah 0 . Akan tetapi, sinyal yang dihasilkan mempunyai nilai yang berubah-ubah, seharusnya jika sensor gyroscope dalam keadaan diam, keluarannya akan sama dengan nilai offset-nya. Hal ini dikarenakan sensor gyroscope mempunyai nilai bias. Gambar 10 (b) menunjukan grafik angle rate sensor gyroscope ketika diberi rotasi. Pada saat grafik menurun menunjukkan bahwa sensor gyroscope berotasi searah jarum jam yang ditandai dengan mengecilnya nilai keluaran sensor gyroscope. Sedangkan pada saat grafik menaik menunjukkan bahwa sensor gyroscope berotasi berlawanan arah jarum jam yang ditandai dengan membesarnya nilai keluaran sensor gyroscope.

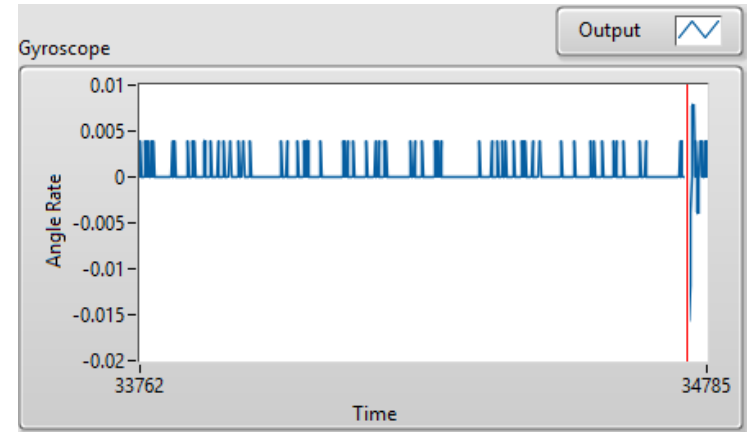

(a)

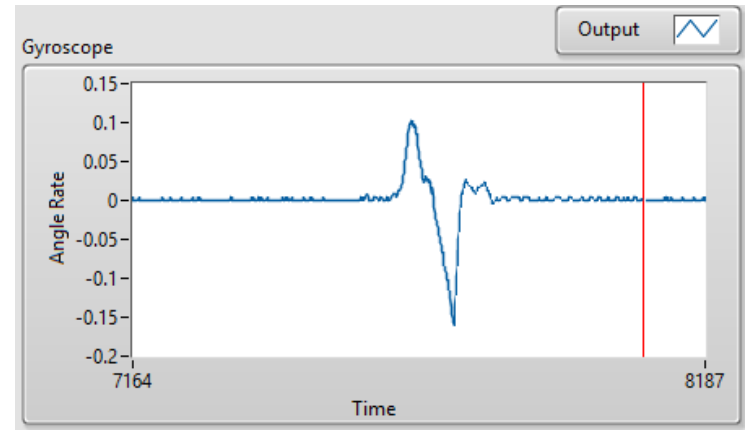

(b)

Gambar 10. Angle rate sensor gyroscope ketika (a) Diam, (b) Berotasi

\section{Perangkat Lunak}

Selanjutnya pengujian terhadap algoritma complementary filter dilakukan. Pengujian ini bertujuan untuk melihat respon keluaran sudut kemiringan accelerometer, kecepatan sudut gyroscope dan hasil penggabungan (fusion) kedua sensor tersebut. Berdasarkan pengujian complementary filter, maka penentuan nilai time constant $(\tau)$ dengan beberapa variasi dan pengaruh penentuan koefision filter dilakukan. Penentukan nilai time constant $(\tau)$ pada koefisien filter dilakukan dengan menggunakan waktu sampling $(\mathrm{dt})$ sebesar 10 $\mathrm{ms}$. Pada saat berotasi, beberapa variasi nilai time constant yang akan dilakukan saat pengujian adalah $5 ; 1 ; 0,3$; dan 0,01. Beberapa grafik yang menunjukkan adanya varisi time constant pada saat model balancing robot berotasi ditunjukkan pada Gambar 11. Berdasarkan grafik tersebut, diperoleh hasil nilai koefisien filter 0,997 pada time constant $(\tau)$ 0,3 detik. Sinyal keluaran complementary filter ini memiliki hasil yang stabil dibandingkan dengan complementary filter sebelumnya. Oleh sebab itu, maka nilai time constant yang digunakan untuk aplikasi balancing robot adalah 0,3 detik.

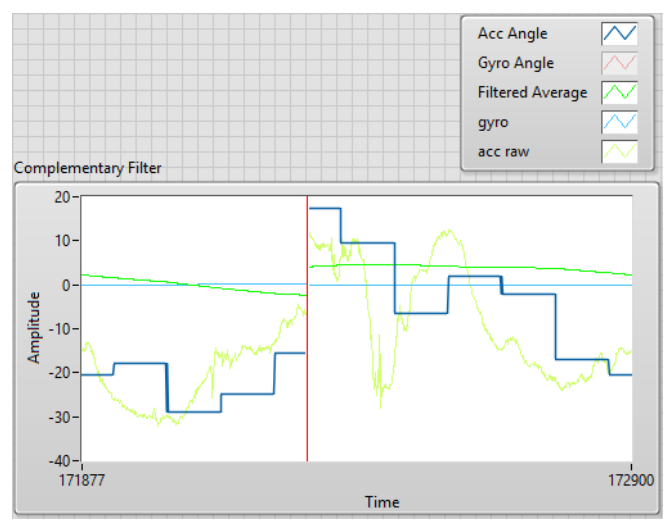

(a)

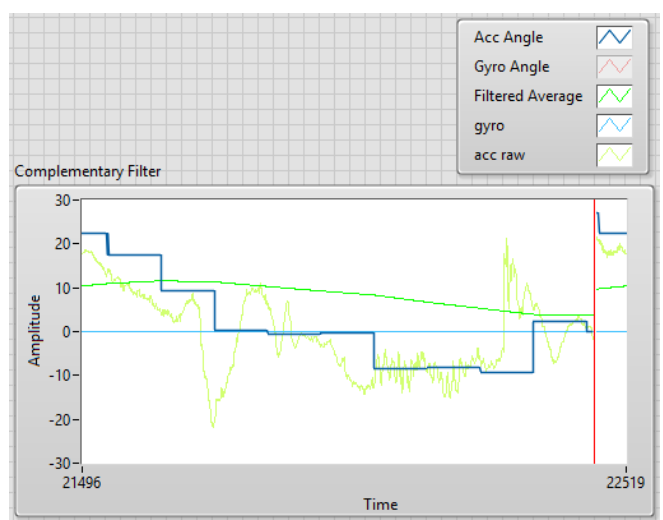

(b)

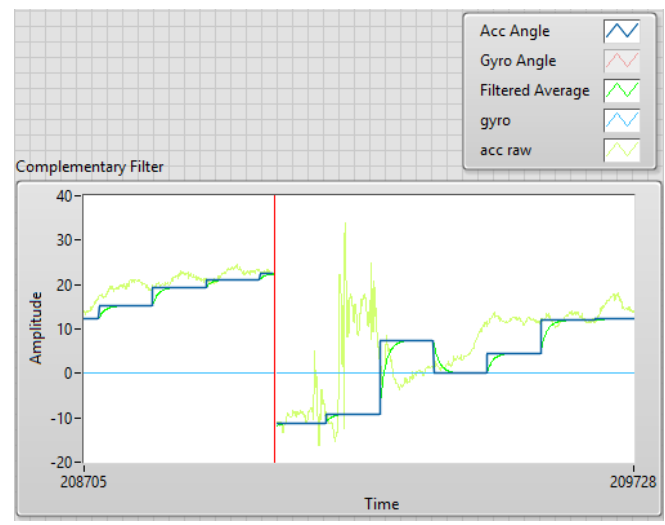

(c) 


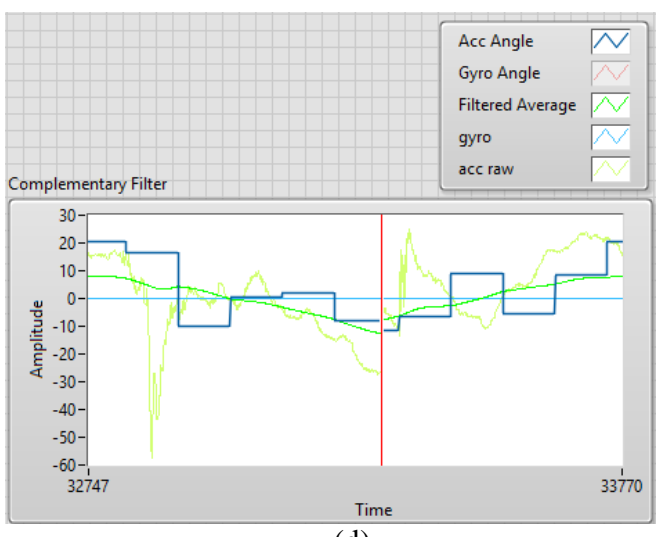

(d)

Gambar 11. Pengujian time constant ( $\tau$ ) untuk (a) 5 ; (b) 1 ; (c) 0,01 ; dan (d) 0,3

Tahap berikutnya adalah pengujian tunning gain PID pada model balancing robot yang dilakukan dengan dua metode, yaitu metode Ziegler-Nichols dan trial and error. Pada penelitian ini, model balancing robot didekati berdasarkan inverted pendulum [12]. Adapun hasil parameter $\mathrm{CoG}$ model balancing robot ditunjukkan pada Gambar 12 dan Tabel 2.

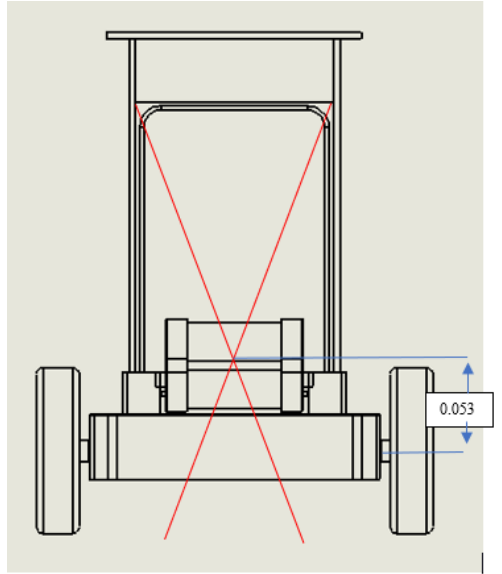

Gambar 12. CoG balancing robot

Tabel 2. Parameter pengujian $\mathrm{CoG}$

\begin{tabular}{lcc}
\hline \multicolumn{1}{c}{ Parameter } & Simbol & Nilai \\
\hline Massa Balancing robot & $\mathrm{m}$ & $0,739 \mathrm{~kg}$ \\
Panjang Balancing robot & $\mathrm{l}$ & $0,053 \mathrm{~m}$ \\
Gaya Gesekan & $\mathrm{b}$ & $0,1 \mathrm{~N} / \mathrm{m} / \mathrm{s}$ \\
Konstanta Gravitasi & $\mathrm{g}$ & 9,81 \\
Momen Inersia Robot & $\mathrm{I}$ & 0,00069 \\
& & $\mathrm{kgm}^{2}$ \\
\hline
\end{tabular}

Pada sistem kontrol PID, berdasarkan metode ZieglerNichols, diperoleh nilai $\mathrm{K}_{\mathrm{u}}=100$ dan $\mathrm{T}_{\mathrm{u}}=0,19$, sehingga didapat gain proportional integral yaitu $\mathrm{K}_{\mathrm{p}}$ $=45$ dan $\mathrm{K}_{\mathrm{i}}=59,94$. Berdasarkan pengujian nilai gain tersebut, model balancing robot sering berosilasi. Oleh sebab itu, nilai gain ini tidak dipilih untuk diaplikasikan pada kontroler yang digunakan. Adapun pengujian menggunakan metode trial and error dilakukan dengan mengubah nilai konstanta $K_{p}$ dan $\mathrm{T}_{\mathrm{i}}$, kemudian melihat respon sistem model balancing robot atas sudut kemiringan yang ditampilkan. Pengujian konstanta $K_{p}$ menggunakan tiga buah nilai yaitu 5; 10; dan 15. Sedangkan nilai konstanta $T_{i}$ menggunakan dua buah nilai 0,001 dan 0,002. Hasil pengujian metode ini ditunjukkan pada Gambar 13 . Berdasarkan perbandingan grafik respon sistem pada model balancing robot atas nilai konstanta $\mathrm{K}_{\mathrm{p}}$ dan $\mathrm{T}_{\mathrm{i}}$ dengan menggunakan pengamatan visual, maka respon sistem yang terbaik ditunjukan pada Gambar 13 (a) dengan nilai gain $K_{p}=5$ dan $T_{i}=0,001$.

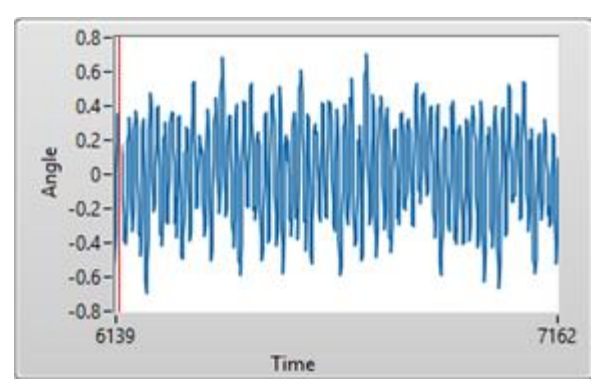

(a)

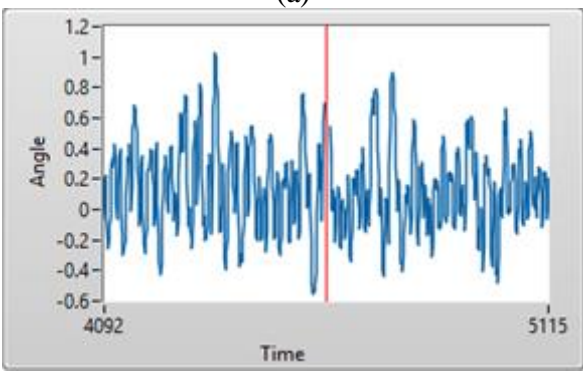

(b)

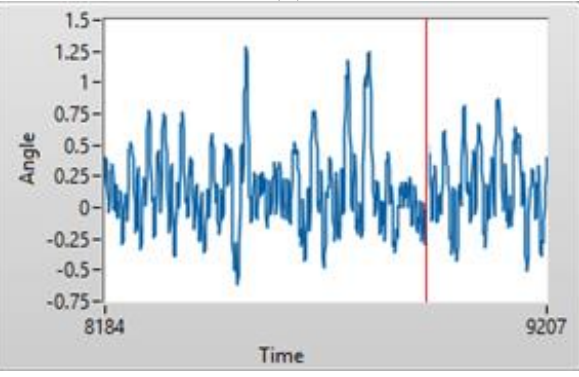

(c)

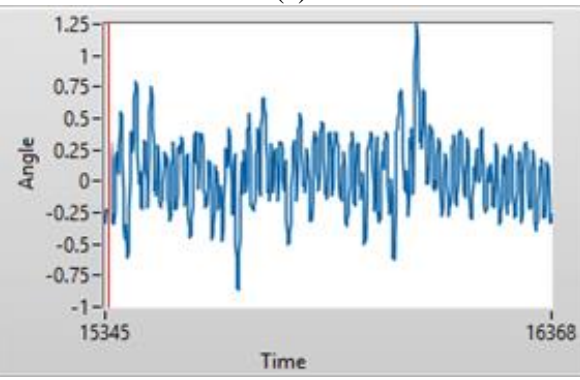

(d)

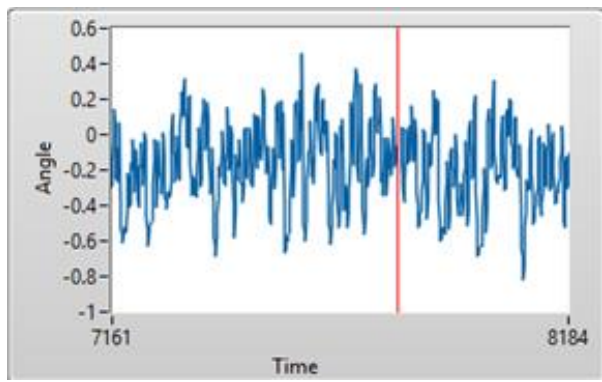

(e) 


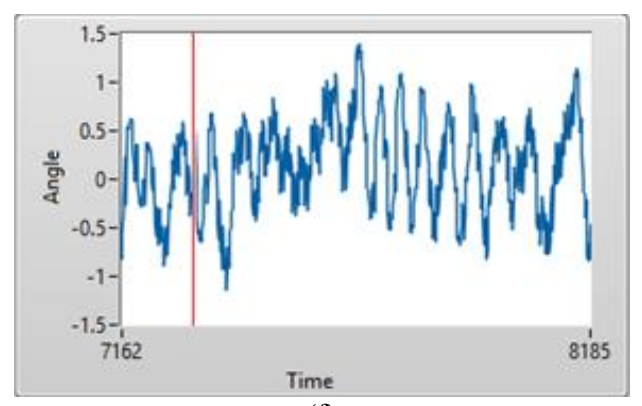

(f)

Gambar 13. Respon sistem pada balancing robot untuk nilai gain (a) $\mathrm{K}_{\mathrm{p}}=5$ dan $\mathrm{T}_{\mathrm{i}}=0,001$; (b) $\mathrm{K}_{\mathrm{p}}=10$ dan $\mathrm{T}_{\mathrm{i}}=$ 0,$001 ;$ (c) $\mathrm{K}_{\mathrm{p}}=15$ dan $\mathrm{T}_{\mathrm{i}}=0,001 ;$ (d) $\mathrm{K}_{\mathrm{p}}=5$ dan $\mathrm{T}_{\mathrm{i}}=0,002$;

(e) $\mathrm{K}_{\mathrm{p}}=10$ dan $\mathrm{T}_{\mathrm{i}}=0,002$; (f) $\mathrm{K}_{\mathrm{p}}=15$ dan $\mathrm{T}_{\mathrm{i}}=0,002$.

\section{Kesimpulan}

Artikel ini menyampaikan hasil penelitian tentang model balancing robot yang kedepannya akan dikembangkan sebagai model alat transportasi ramah lingkungan untuk tenaga medis di lingkungan rumah sakit. Berdasarkan conceptual design, model balancing robot didesain dengan konfigurasi dasar menggunakan dua roda, posisi mikrokontroller tegak, dan beban yang dibawa oleh model balancing robot diletakkan di bagian atas. Berdasarkan pemprograman menggunakan LabVIEW 2015, diagram blok model balancing robot telah dibuat. Untuk kontrol loop complementary filter diperoleh nilai time constant $(\tau)=0,3$ dan nilai koefision filter sebesar 0,997. Adapun model balancing robot menggunakan dua buah motor DC yang dikontrol menggunakan kontrol PI. Berdasarkan hasil pengujian menggunakan metode Ziegler-Nichols dan trial and error, maka didapatkan nilai gain kontrol PI yang optimal adalah $\mathrm{K}_{\mathrm{p}}=5$ dan $\mathrm{K}_{\mathrm{i}}=0,001$.

\section{Ucapan Terima Kasih}

Penelitian ini didukung dengan dana dari Fakultas Teknik Universitas Diponegoro melalui hibah Penelitian Dasar Tahun 2018.

\section{Daftar Pustaka}

[1] fRonald Ping M.C., Karl A. Stol, C. Roger Halkyard. 2013, "Review of modelling and control of two-wheeled robots." Annual Reviews in Control, Elsevier, Vol. 37 (1), 89-103.

[2] Palacin J., PallejaT., Valganon I., Pernia R., Roca J. 2005, "Measuring coverage performances of a floor cleaning mobile robot using a vision system." In: Proceedings of the IEEE International Conference on Robotics and Automation, 4236-4241.

[3] Seung-Nam Y., Jae-Ho J., Chang-Soo H. 2007, "Auto inspection system using a mobile robot for detecting concrete cracks in a tunnel." Automation in Construction, Elsevier, Vol. 16 (3), 255-261.

[4] Evans J.M. 1998, "HelpMate: anautonomous mobile robot courier for hospital." in: Proceedings of IROS'98, 1695-1700.
[5] Krzystof J. Kalinski, Michal Mazur. 2016, "Optimal control of 2-wheeled mobile robot at energy performance index." Mechanical Systems and Signal Processing, Elsevier, Vol. 70-71, 373-386.

[6] Tengku M., Darlis H., Abdul M. 2017, "Remote control komunikasi robot berbasis pergerakan tangan pada smartphone menggunakan metode logika fuzzy." Jurnal Inspirasi, Vol. 7, 52-59.

[7] Sangtae K., Jungmin S., SangJoo K. 2011, Development of a two-wheeled mobile tilting and balancing (MTB) robot. Proc of $201111^{\text {th }}$ International Conference on Control, Automation and Systems (ICCAS), 1-6.

[8] Xiaogang R., Jing C., 2010. On-line NNAC for a balancing two-wheeled robot using feedbackerror-learning on the Neurophysiological mechanism. Journal of Computers, Vol 6 (3), 489-496.

[9] C. Gonzalez, I. Alvarado, D. Munoz L.P. 2017, "Low cost two-wheels self balancing robot for control education." IFAC-PapersOnLine, Elsevier, Vol. 50 (1), 9174-9179.

[10] Shandy H.T, Rusdhianto E, M. Rameli. 2012, Perancangan dan implementasi kontroler PID untuk pengendalian tegangan pada generator set.” Jurnal Teknik ITS, Vol. 1, 2301-9271.

[11] Ahmad N. K. N., Mohd. A. A., Riduwan G., Nasrul S. P. 2011, Performance comparison between fuzzy logic controller (FLC) and PID controller for a highly nonlinear two-wheels balancing robot. Proc. of First international conference on informatics and computational intelligence (ICI), 176-181.

[12] Y. Kim, S.H. Kim, Y.K. Kwak. 2006, Improving driving ability for a two-wheeled invertedpendulum-type autonomous vehicle. Proc. of the Institution of Mechanical Engineers, Part D: Journal of Automobile Engineering, 165-175. 